\title{
Perspectives of meaningful work in a high-burnout academic medical center: a discourse analysis
}

\author{
Timothy Atkinson, ${ }^{1}$ Molly Gathright, ${ }^{2}$ James Clardy, ${ }^{2}$ Carol Thrush, ${ }^{3}$ Erick Messias ${ }^{2}$ \\ ${ }^{1}$ Department of Internal Medicine; ${ }^{2}$ Department of Psychiatry; ${ }^{3}$ Department of Surgery, University of Arkansas for Medical Sciences, \\ Little Rock, Arkansas, USA
}

\begin{abstract}
We conducted a discourse analysis of meaningful work from the perspective of healthcare workers in an academic medical center where we previously observed relatively high levels of personal burnout (52.7\%) and work-related burnout (47.5\%), all based on the Copenhagen Burnout Inventory survey. Burnout is often studied as psychological condition characterized by exhaustion, depersonalization, and feelings of inefficacy or lack of career achievement, but as demonstrated in this analysis, burnout loses its meaning because healthcare professionals provide a robust account of what makes work meaningful to them despite their prevalence of burnout. Healthcare professionals exhibit a higher level of burnout compared to workforce members in other organizations. Physicians specifically are at high risk for exhibiting symptoms of burnout and work-life imbalances. In addition, burnout manifests itself early in the physician's career compared other occupations, and in our sample was prevalent among nurses, too. In this discourse analysis of written answers to the survey question, In ten words or less describe what makes your work meaningful? healthcare professionals provide an account of meaningful work that maintains its value in this environment despite the level of burnout, especially when healthcare professionals can use their hard-earned knowledge to make a difference in the lives of people, and observe the results of their work, which is beyond just taking care of patients. Nurses accounted for meaningful work in terms of close connections with patients, while being closely focused on ability to provide professional care and experiencing the outcomes associated with that care, and knowing that they have done a good job. Physicians were patient focused, and they expressed meaningful work in terms of making a difference, and using their abilities to help patients. Basic scientists accounted for meaningful work in terms of their training and abilities to use science for the betterment of others in society.

Contributions: TA: conceptualization of the burnout and meaningful-work studies, qualitative design, research questions, survey in-
\end{abstract} strument design, edited and submitted the IRB protocol, interpretations, prepared the corpus, text analytics, discourse analyses, literature review, wrote and prepared manuscript; MG: conceptualization of the burnout and meaningful-work studies, qualitative design, research questions, survey instrument design, edited the IRB protocol, interpretations; JC: conceptualization of the burnout and meaningful-work studies, qualitative design, research questions, survey instrument design, edited the IRB protocol, interpretations; CT: conceptualization of the burnout and meaningful-work studies, qualitative design, research questions, survey instrument design, wrote and edited the IRB protocol, interpretations, edited manuscript; EM: statistician and data analyst, checked the interpretations, edited manuscript.

Conflict of interest: the authors declare no potential conflict of interest.

Funding: none.

Received for publication: 21 May 2018.

Revision received: 30 July 2018.

Accepted for publication: 30 July 2018.

This work is licensed under a Creative Commons Attribution NonCommercial 4.0 License (CC BY-NC 4.0).

CCopyright T. Atkinson et al., 2018

Licensee PAGEPress, Italy

Qualitative Research in Medicine \& Healthcare 2018; 2:73-83

doi:10.4081/qrmh.2018.7572

\section{Introduction}

\section{What is meaningful work?}

The field of organizational development uses the concept of meaningful work to study how people create positive work environments. ${ }^{1-6}$ These thoughts align well with meaningful work as defined by Steger et al. ${ }^{7}$ and Martela and $\mathrm{Pessi}^{8}$ who steered away from the study of what makes workplaces negative to focus on the positive impact of meaningful work. Meaningful work in the organizational development sense, however, might be individualized and not involve the act of helping others in a charitable sense at all. ${ }^{7,8}$ Meaningful work can be very personal, and people do not necessarily share the same experiences with the same kinds of work. Each individual decides what work is meaningful to him or her, and will convey that understanding in different ways. As Martela and Pessi note, it could involve either work that helps one achieve self-realization or work that makes one feel as though they are contributing to a broader purpose. ${ }^{8}$ By examining commonalities in language use and word clusters among groups, we discovered what 
meaningful work might mean for groups or organizations in an academic medical center. Along the way we discovered that meaningful work in the good works sense is really the soul of meaningful work in the technical sense, too. Whether talking about meaningful work as an organizational phenomenon or as a charitable act, we found that the selfless' focus on service to other people is the core to perceptions of meaningful work in this particular organization.

\section{Literature review}

In this literature review, we set the parameters and background for our overall qualitative question, but we wanted to avoid finding information that would influence our interpretations of the voices of our respondents. Below, we examine the effects of meaningful work, and some of the definitions in general, but does not necessarily say what meaningful work is for a particular population. The rest of our argument develops by way of written discourse and texts gathered during the study.

\section{Workplace spirituality and meaningful work}

Meaningful work is often studied as one of three dimensions of workplace spirituality (WPS) along with a sense of community, and value of organization. ${ }^{9}$ Within WPS, meaningful work is often associated with greater job satisfaction and greater work engagement. ${ }^{10,11}$ Hassan et al. noted that it is important to emphasize a person's values, incorporating their sense of community to produce meaningful work. ${ }^{9}$ Further, Kazemipour and Amin, studying WPS, noted that meaningful work contributes to organizational citizenship behavior, another positive workplace concept. ${ }^{12}$ None of these studies seem to have isolated meaningful work from the other components of WPS. One explanation could be that WPS instruments included items measuring meaningful work, which are normed with these other dimensions of WPS. Another explanation could be because the focus of was not on meaningful work alone, but rather on mediating factors such as trust and work engagement, or outcome measures such as organizational commitment.

Steger et al. ${ }^{7}$ and Martela and Pessi, ${ }^{8}$ on the other hand, do isolate meaningful work into its own components: my work has significance, my work contributes to broader meaning in life, and my work contributes to the greater good. We used Steger et al.'s WAMI study as the guiding document for meaningful work for our qualitative study because of the focus on meaningful work alone. ${ }^{7}$ Still, these parameters say nothing about the actual meaningful work people are doing in an organization. The range of meaningful work is vast, given the number of occupations and careers that exist in our world.

\section{Wellness and meaningful work}

It is clear that meaningful work, however it is defined, is necessary for retaining and attracting people to the healthcare workforce just as much as anywhere else. ${ }^{13} \mathrm{Ac}-$ ademic medical centers work at the crossroads of education, and the time-constrained activity of patient care, and the need to nurture relationships, education, and self-reflection for a balanced and more meaningful work environment. ${ }^{14}$ The construct of meaningful work is often studied as an important component of wellness and as a way to combat burnout. For instance, using the effort-reward imbalance (ERI) model, Rasmussen et al. studied emotional exhaustion (EE) and depersonalization (DP) (Two Maslach burnout dimensions $)^{1,2}$ in psychosocial oncologists and found that high levels of meaningful work predict lower levels of EE and decreased DP, however only $2 \%$ of the variance was accounted for using the ERI model. ${ }^{15}$ The authors concluded that meaningful work could be added as an extension of the ERI model. In a study of U.S. neurologists, Busis, Shanafelt, Keran et al. found that burnout was indeed reduced because of the meaning neurologists found in their work. ${ }^{16}$ But the unanswered question in these studies is how people talk about meaningful work in healthcare. They presented no discourse or text about what the respondents feel meaningful work is. Also, these studies are based on specific specialty groups within healthcare who might talk about meaningful work differently than other groups in healthcare. In a study more closely aligned with ours, Schrijver, Brady and Trockel conducted 19 focus group sessions across 17 clinical departments and found that participants' meaningful work emerged as a key component to work motivation. ${ }^{17}$

In contrast to these findings, meaningful work can sometimes have a negative impact on employee wellness; Jones and Griep call this relationship the double-edged role of meaningful work. ${ }^{18}$ Work can become so important, meaningful, and absorbing, that other aspects of wellness are compromised. Cain, Taborda-Whitt, Frazer, et al. supported these findings, noting that their qualitative data from a mixed methods study illustrated an association between meaningful work and feelings of depletion. ${ }^{19}$ Jager, Tutty and Kao also found that engrossing meaningful work and a sense of calling could both be negatively associated with each other, noting that higher burnout rates overpowered the sense of meaningful work. ${ }^{20}$ Bendassolli also found that meaning making in work can be hindered by the way a person experiences emptiness. ${ }^{21}$ It is interesting to note at this point that when we begin to describe our interpretations of the texts and discourse, there can be some sense that the pursuit of meaningful work is also contributing to burnout in some people. In other words, the unintended consequences of pursuing meaningful work could result in negative outcomes, and people with a passion about the elements that make their work meaningful could actually be experiencing burnout.

\section{Connectedness and meaningful work}

Further, in a qualitative research study that employs a categorical content analysis, van Iersel et al..$^{22}$ noted that scant qualitative evidence exists about nurses' perceptions 
of meaningful work. Their research is important for the current study because it is also qualitative, used a content analysis method, and focused on a prominent group in our sample, nurses. The qualitative themes that emerged from the van Iersel study were labeled as connections, contributions and recognition. ${ }^{22}$ These are very general terms that do not necessarily describe the actual tasks that contribute to meaningful work. van Iersel et al..$^{22}$ concluded that meaningful work is most likely present in an organizational environment that supports continuous learning, teamwork, and effective management, but task orientation, stressful relationships and divisive management likely hinder meaningful work. The authors used the following labels to define nursing roles such as advocate, catalyst and guide and caring presence. This study echoes other studies that assert the importance of connections and collaborations in healthcare to create meaning in work. ${ }^{23,24}$ Meaningful work, meaning making, connectedness and even transcendence are all associated outcomes of spirituality in the workplace, which we discussed earlier. ${ }^{23}$ Other studies have shown both positive and negative effects of strong connections, especially Tummers and Bronkhorst, who used the leader-member exchange leadership model to study meaningful work, and noted a strong connection with the leader can often result in meaningful work. ${ }^{25}$

In summary, meaningful work is important to workforce sustainability, reducing burnout in terms of depersonalization and emotional exhaustion, and for overall health and motivation of the workforce in general. In contrast to this, meaningful work could also be a culprit contributing to work burnout because healthcare carries with it many intrinsically meaningful tasks and occupations. For the most part, we know people strive for finding meaning in their work because they often spend more time at the workplace than anywhere else.

\section{Study objectives}

The overall goal of the study is to determine the perspectives of meaningful work among physicians, health providers and basic scientists working in an environment that is at risk of high burnout. We wanted to know what makes work meaningful to people, and we wanted them to use their own words. Second, we wanted to know what makes work meaningful to academic healthcare employees, so we can focus on how to help facilitate the reduction of burnout and increase well-being in the academic medical center environment.

\section{Research questions}

What are the perspectives of meaningful work among employees in an academic health center? What words do health care professionals choose when they discuss meaningful work in an academic healthcare environment that has been found to be highly prevalent for the risk of occupational burnout?

\section{Materials and Methods}

Research Design. We used a concurrent embedded design because we embedded a single qualitative prompt in a larger quantitative survey to examine meaningful work from a discourse and meaning perspective. ${ }^{26}$ In this report, we are only reporting the results of the qualitative question.

Prompt. Our embedded qualitative prompt was, In 10 words or less, describe what makes your work meaning$f u l$. The survey designers stopped at 10 words for two reason: i) they felt that the quantitative survey was already too long, and that adding more qualitative questions would encroach on the already valuable time of the respondent population; and ii) they also felt the need to have the respondents keep their comments brief so that they could say the first things that came to mind and not feel like they had time to clarify their responses. Respondents mostly adhered to the ten-word prompt, but others responded at length, which generated a large corpus about meaningful work. This was an excellent unintended consequence of the design. Given the nature of the question, the number of responses, and the nature of the data (all texts), we determined that linguistic and discourse analytic methodologies were appropriate for extracting meaning from the texts. The large body of responses would lend themselves to corpus linguistic analysis, and the more individual or in vivo codes would lend themselves better to discourse methods. Naturally, we discounted case study, phenomenology, narrative and grounded theory approaches because we only used one data-gathering method, we were limited to the 10 words, and did not spend time in the field doing interviews to reach a level of saturation with the data..$^{27,28}$

Institutional Review Board (IRB) Approval. The study was approved by the IRB using expedited approval procedures because the study was minimal risk, used extensive encryption keys to separate respondent identities from results, and blocked the research team from linking results and keys.

Respondent Characteristics. We targeted data collection from a single academic medical center in the southern region of the United States, focusing primarily on workforce members with direct patient interaction on a daily basis, and secondly from basic scientists. We collected text responses to the prompt from the following groups, at the following rates (Table 1).

The number of respondents in qualitative research does not necessarily have any bearing on generalizability or statistical significance because that is not the goal of qualitative research. Our goal was to capture as much language use as necessary to extract language about meaningful work. In our case, we used all responses to generate patterns and codes. Nurses were the largest respondent group, and their discourse dominated the answer to the original prompt, and ultimately the research question. Nonetheless, we were able to extract several distinctive 
patterns in the discourse that distinguished the different groups from one another. To facilitate group level analyses of nurses, physicians, and basic scientists, we combined the nurse respondents together in one group (regardless of credential or education), and combined all physician respondents together as well.

Preparation of the Corpus. The corpus (all the group responses together) was first prepared by eliminating stop words such as $a$, and the, and isolating words from colons, periods and commas. Textual data was further tokenized to extract words to their base unit. We also employed frequency counts and collocations (Figure 1).

Tools used. We used AntConc to conduct word counts and help discover words in context using Keyword In Context Analysis or KWIC as well as collocations (regularly occurring and similar sentence structures). ${ }^{29}$

\section{Interpretation philosophy}

Through this analysis, we simply interpreted word patterns, clusters, and phrases, and in no way intended generalizability or statistical inference, as this is a qualitative, interpretive analysis. Our interpretations were therefore based on simple linguistic analysis by examining specific lexical chains (sequences of related nouns and verbs used by a group). We discovered these chains using the KWIC and collocation analysis tools to reveal where respondents used shared language patterns to convey shared meaning, especially in a given setting. ${ }^{30,31}$ The term frequency, collocation, KWIC, and interpretation procedures are all interrelated and interactive, and not linear. The language under investigation is derived from a corpus-driven methodology and is analyzed partly within the framework of Thompson's functional grammar. Discourse analyses that employ functional grammar examine how the structure of particular sentences chosen by a speaker reflects how speakers interpret and produce information. In analy- ses of some participant answers, the authors also draw from the Processes/Phenomenon framework (Table 2).

\section{Types of coding used}

We employed pattern coding, which involves commonly used phrases, and in vivo coding, which uses respondent's own words to convey the meaning. ${ }^{32}$ Both coding approaches were easily employed because the collocation and KWIC analysis revealed these patterns almost immediately. Because the study group was blinded to respondents and the links to codes, we did not employ member checking to check our interpretations with respondents.

\section{Results and Discussion}

Multiple levels of analysis and interpretations emerged from the data. We borrowed advice from the field of Organizational Development (OD) and limited our analysis to the Organizational, Group, and Individual levels of analysis. ${ }^{5}$ Each discussion includes some orga-

Table 1. Types of groups and number of responses.

\begin{tabular}{lc}
\hline Group & Responses \\
\hline Advanced Practice Nurses & 49 \\
\hline Physicians & 180 \\
\hline Licensed Practice Nurses & 24 \\
\hline Registered Nurses & 534 \\
\hline Resident/Fellow Physicians & 40 \\
\hline Basic Scientists $\quad 87$ \\
\hline
\end{tabular}

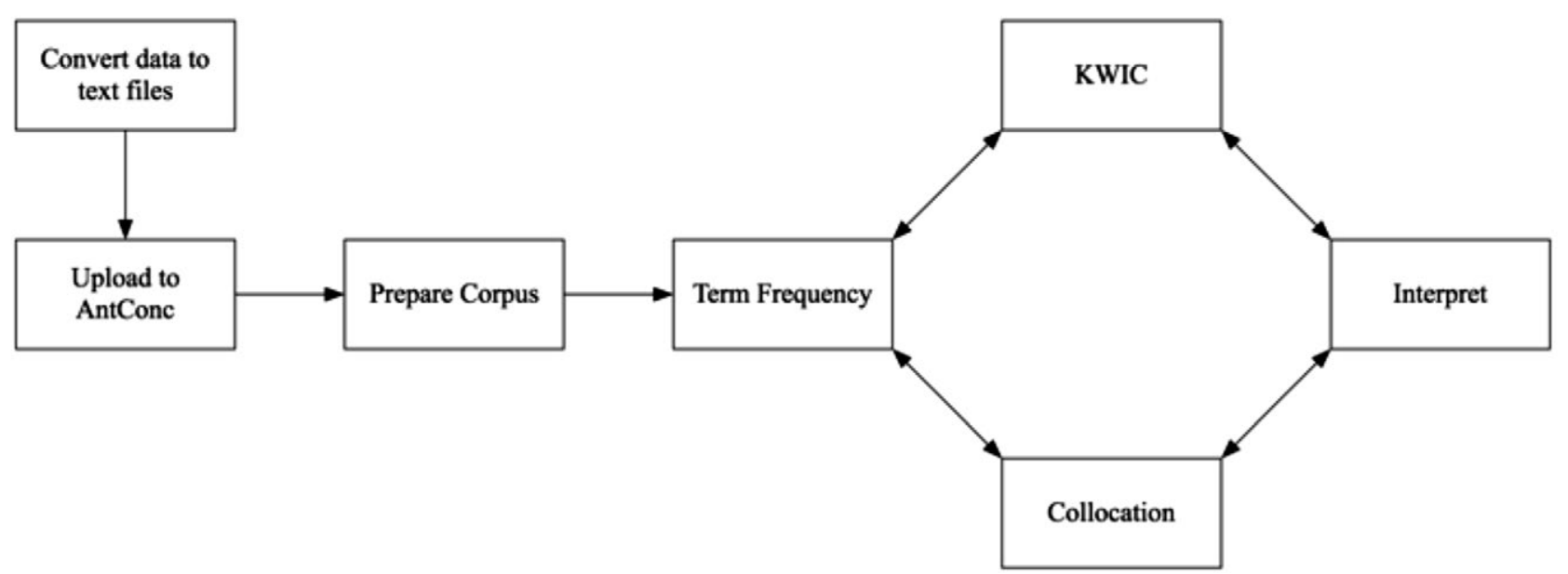

Figure 1. Data handling and process. 
Table 2. Interpretive framework. ${ }^{30,31}$

\begin{tabular}{ll}
\hline Processes/Phenomenon & Examples \\
\hline Mental & Think, see, hear, know, the senses, believe, the mind \\
\hline Material & Delivering, providing, taking, crushing, doing, etc. \\
\hline Situated Meanings & Health, patient, care, science, discovery, etc. \\
\hline Social Languages & Interactions with patients, other providers \\
\hline Discourse Kits & Common word usage \\
\hline Intertextuality & Borrowed or shared phrases \\
\hline
\end{tabular}

nizational level interpretation, which naturally includes an examination of language use among all groups, and even individuals. The analysis then flows down to a focus of each group alone, which almost always includes some examination of individual responses or individual level analysis. In all, organizational, group and individual analyses are included to show contrasts, make comparisons, and differentiate group differences.

We began with a word frequency analysis to provide insight into the organization level attitudes about meaningful work. Frequency counts revealed high-usage keywords at the organization level such as patients, patient, helping, care, difference, being, and making (Table 3).

Given the frequency of words, and an examination of Table 3, we decided to look at word clusters and groupings that occurred at the highest frequencies patients, $p a-$ tient, helping, care, and $m y$. We discovered the following word clusters in high use among our organization of study: i) A difference; ii) Able to; iii) Making a; iv) My patients; v) Helping patients; vi) Being able.

We can say with some certainty that perceptions of meaningful work held by participants in this study are comprised of wanting to make a difference in the lives of patients using their abilities. Though this is not a new discovery, it provides evidence that meaningful work is indeed connected to the betterment of others from an organizational standpoint. Also, given that prior research indicated high levels of burnout among the employees in this sample, it illustrates that people in this particular organization have not lost sight of what makes work meaningful. Taking each organization perception in turn we examined more closely the themes of making a difference and helping patients.

\section{Making a difference in people's lives}

All groups within the organization used some form of the pattern making a difference. Turning to the group level, nurses and physicians alike talked of making a difference in the lives of patients or in people's lives. As noted in the following sample some respondents used $\mathrm{pa}$ tients and others used people when talking about Making a difference:
$\mathrm{RN}$ : Making a difference in people's wellbeing; Physician: Making a difference for my patients. APN: Making a difference, educating patents. Resident: Making a difference physically and emotionally with patients.

Table 3. Word frequency analysis (Organizational Level).

\begin{tabular}{|c|c|}
\hline Word & Frequency \\
\hline Patients & 306 \\
\hline Patient & 152 \\
\hline Helping & 143 \\
\hline Care & 131 \\
\hline My & 114 \\
\hline Difference & 84 \\
\hline Being & 83 \\
\hline Making & 76 \\
\hline Life & 64 \\
\hline Help & 58 \\
\hline Able & 56 \\
\hline Lives & 55 \\
\hline People & 55 \\
\hline Others & 54 \\
\hline Seeing & 51 \\
\hline Outcomes & 44 \\
\hline Make & 43 \\
\hline Better & 42 \\
\hline Positive & 41 \\
\hline Health & 37 \\
\hline Knowing & 36 \\
\hline Need & 35 \\
\hline Good & 34 \\
\hline Work & 30 \\
\hline Families & 29 \\
\hline
\end{tabular}


At the individual level, one basic scientist found meaning in work by making a difference, but said, Making a positive impact on research... This particular phrase made us aware of some sharp contrasts between groups as we studied the language use more closely. These differences are highlighted in the group level analysis that follows this section.

\section{Ability and able}

The word ability appeared in so many different patterns that we examined these clusters. The patterns that emerged in the use of the word ability or able held some commonalities and differences across all professional groups at the organizational level. At the group level, in response to the prompt, What makes your work meaningful?; One Advanced Practice Nurse (APN) said, The ability to connect with my patients, which decreased the perceived distance between patient and caregiver. Physicians, on the other hand, responded such as, the ability to make a difference, the ability to set standards of care, and the unique ability to affect peoples' lives, which can be broad and open to interpretation as a greater distance between patient and caregiver, that perhaps their training as an expertise in medicine requires their utmost objectivity, and that perhaps there is no room for emotional connections because those emotional connections might interfere with scientific, data-driven evaluation of the patient. In practice among physicians, it is always the patient. It is not $m y$ patient. It is rarely my patient presented with $x$ symptoms but more the patient presented with $x$ symptoms. Physicians did not express patterns of word usage such as the ability to connect with patients or to connect with $m y$ patients. Physician use of the word ability seems to be tied to utility of having the knowledge to serve people and make them better.

In contrast, Registered Nurses and Licensed Practice Nurses responded in ways that indicated their ability also came from training, but they tied it to the relationship with the patient in a more substantive way, such as: the ability to make meaningful change, ability to make a difference in their care, and ability to help patients get better. Again, nurses tend to exhibit a closer relationship to the patient in language use than other groups, making meaningful work more about the relationship than the process. We are not saying physicians do not care for the relationships with the patient, but as we reveal through this analysis, we became increasingly convinced that education and training has forced them to be more objective than relational. These findings come as no surprise, but we must not lose sight of the original question. Ability and process makes work meaningful for physicians, while ability and relationships with patients are what makes meaningful work for nurses. We observed some of this contrast when examining the language of one resident physician who said, the ability to change the trajectory of a family. To us, this is a high impact statement, and it again signals that the actor is providing a material service to help the patient's long-term sustainability. As we continue, this particular theme emerges among physician discourse throughout this particular corpus. Physicians seem to be saying, not just healing for now, but healing for a lifetime. The resident physician's language aligns with the rest of the physicians in terms of long-term impact on patient care as a material process or a link in a larger chain of events in a patient's life.

On the other hand, nurses and physicians alike seemed to use the being able word cluster along with the word help or some form of the word help as exemplified by the following phrases by nurses: i) Being able to help a patient; ii) Being able to get done what needs to get done; iii) Being able to help patients; iv) Being able to help patients have a successful procedure; v) Being able to provide patients with the care they need.

Nurses along with physicians found meaning in their work by being able to help patients. We found it interesting that the phrase being able emerged in such a dominant pattern, but we interpreted this to mean that the academic medical center provides plenty of opportunities for the healthcare workforce to exercise their abilities in a unique and substantive way to impact the lives of others, burnout or not. Our respondents seem to consider it a privilege to be able to help people in their time of need, which supports the research on meaningful work that suggests doing good works results in intrinsically meaningful work.

At the organizational level analysis we can also see that helping is a big theme especially when it collocates with patient. A closer examination of the word cluster helping patients reveals that helping patients is only part of the story. Almost all groups used the grouping helping patients alone or in some context as exemplified by the following sample of phrases:

$\mathrm{RN}$ : Helping patients achieve their goals Physician: Helping patient and teaching students. Resident: Helping patients cope or live better.

If we were to stop the analysis with just word counts and frequently occurring clusters, each group would be practically the same as far as meaning and interpretation. The word count only tells us when a group of people used the same words to describe the phenomenon. As discussed previously, it is not surprising to find physicians and nurses using the word patient in daily discourse, as it is part of the discourse kit in academic health centers. In order to get at true meaning, it is necessary to look at group level usage in context to examine the use of the word patient and patients and their collocation with other word clusters.

At the organization and group levels, we found many commonalities in language use, especially for being able to make a difference in the lives of people or patients, and helping patients. The essence of the group level analysis is that having the ability to make a difference in the lives of patients and helping patients is where they find mean- 
ing in their work. To this end, we found that nurses appear to have closer emotional relationships to patients than other groups. When we examined word cluster my patient using KWIC, we found that this interpretation holds mainly for nurses.

\section{More group and individual level contrasts using keyword in context}

\section{Nurses focused on patient outcomes}

When examining the high frequency nouns patient or patients, and applying KWIC and collocation analysis, we discovered patterns that indicated some stark differences between nurses and physicians. For instance, we found that nurses were focused on outcomes when it came to patients by using the actual word outcomes without specificity. The patterns seem to suggest that not only do nurses see meaningful work is a process of taking care of patients and seeing positive outcomes in those patients as exemplified by the following sample:

i) Patient outcomes and the ability to make a difference in their care; ii) Improving patient outcomes; iii) Seeing the reward of good patient outcomes.

Nurses used this phraseology or some variation of these phrases frequently enough to augment our interpretation that nurses find meaning in work through the ability to take care of patients with a focus on outcomes. We believe that this indicates that nurses find meaningful work both in the process of healthcare as well as the relationships they have with their patients such that both contribute to patient outcomes. This is a much stronger interpretation than simply: Meaningful work is taking care of patients. Nurses at this academic medical center are interested in treating the patient while being mindful of positive outcomes driven by sound healthcare decisions. The patterns seem to suggest that nurses use the phrase being able from their years of education and training, and the desire to see positive outcomes is also a function of education, training focused on science and data. The interpretation implies that because nurses have the training, they are able to deliver this service and care to others. Evidence-based medicine is the emphasis for nurses, physicians and anyone taking care of patients. The interpretation would be much less satisfying if we were simply to conclude that nurses like to take care of people. Applying some transitivity analysis to this interpretation, ${ }^{30}$ we find that the phrase indeed represents a material process wherein we have an actor providing a service to a recipient with the hope that an outcome might be achieved. Among nurses, however, it is so much more than that. We would like to interpret this to mean, Nurses like to take good care of people, patients, and families by using a scientific approach and sound reasoning.

We were surprised to find that physicians rarely used this word cluster because their discourse seemed to emphasize the material processes over that of the discourse of nurses. Though the outcomes word cluster is less prevalent in the discourse among physicians, we found that physicians express outcomes in different ways, so we examined this more extensively in the next few sections. Differences in word usages and word patterns emerged to find several variations in the overall interpretation of what makes your work meaningful.

\section{Nurses focused on My patient}

To better examine the interpretation that nurses demonstrate a closer relationship to the patient we looked at the word cluster my patient which was used by nurses more than any other group. Nurses talked about their patients in very personal terms: i) The ability to connect with my patients by taking time to listen ...; ii) Seeing a difference in the lives of my patients; iii) Being able to make a difference for my patients; iv) Bringing joy to my patients; v) being and advocate for my patients; vi) Seeing good outcomes for my patients.

The above sample is an excellent representation of all the responses in the corpus when looking at the my patient cluster. When examined in context, we believe nurses find meaning in their work when they can be a part of the entire process and see positive outcomes, but they couch these expressions in terms of my patient which supports our interpretation that they hold a strong emotional connection to the patient, too. Using the possessive my patients also decreases the distance between caregiver and patient. Within this KWIC analysis there were also several respondents, who talked about connecting with patients, which supports the interpretation that the concept of meaningful work is constructed by a combination of performing a material process plus using specialized training, specifically augmented by personalization.

\section{Physicians focused on patients}

Continuing our group analysis, and using the term $p a-$ tient as a commonality in language use, we turn to physicians and their use of the terms patient, people and person to better understand their relationships with their client and a core reason for their occupation. Physicians most often use the term patient instead of person or people when discussing those in their care, which supports our interpretation that they exhibit lesser emotional connections to patients to respect their objective view of the subject of healthcare. Physicians, however, did not use the term my patient as dominantly as much as nurses did. In fact, only one or two physician respondents used $m y$ patient. In order to examine meaningful work in patients from the physician's point of view, we ran KWIC analysis on the term patient and encountered some interesting patterns at the group-level (Supplementary Table A1). i)... making a difference to patients...; ii) optimize patient care; iii) Improving patient's lives; iv) Having an impact on patient care; v) Giving back to patients; vi) Research 
that affects patient care; viii) Improving the life of my patients.

Analyzing the term patient led us to different conclusions about how physicians view patients. The commonality here is the use of some form of the word to improve, help, impact, and give to patients Though these phrases indicate a positive pattern of physician interactions with patients, we could not ignore the fact the patterns in language use among physicians favored the material processing of patients rather than an emotional connection to patients when compared to nurses. Because they used words like optimize, impact, and research that affects patients, the interpretation emerges as more material than emotional. We also did not ignore the fact that some physicians did exhibit some emotional connection by using my patient, but again, usage was rare. Because making a difference was so prominent in language use among physicians at the organizational level, we examined these patterns still further.

\section{Making a difference}

Though physicians did not use the phrase my patient as often to consider it common usage among this group, we might be led to interpret this to mean physicians have a less connected or personal relationship with their patients than nurses do. We did not want to stop there. Further examination of the discourse, however, revealed that physicians use the cluster making a difference differently when it comes to patients' lives, which is an interesting point of discussion as revealed in their own voices (Supplementary Table A2).

i) I make a substantial difference; ii) Making a difference to patients; iii) Making a difference in the lives of patients and students; iv) Making a difference that gets them back to work/family; v) Making a positive difference in people's lives; vi) The difference I make with patients; vii) When I make a difference in a patient's life.

There are several ways to interpret these patterns of making a difference. For instance, the one statement from above that stands out from the rest of the sample is the phrase making a difference that gets them back to work/family. The impact of this statement compared to the others is that it is outcome driven, not just to heal the patient and process them, rather to be present in the process is to heal the patient, which would allow the patient to return to life and sustain the survival of themselves and their families. Physicians did not use the term outcomes like nurses per se to describe outcomes but spoke more globally in terms of outcomes. Supporting this statement is the fact that, physicians understand their vital role, linking their training and their knowledge, to make a difference in the lives of patients, and that they are the vital link in the patient care process. The patient care process is actually more than just taking care of patients, but healing them such that they can continue to function and have a greater quality of life (the global outcome). It might also be interpreted as physicians showing some emotional distance from the patient more so than nurses when it comes to patient care because they are not saying, Make a difference in my patients' lives rather they are saying in people's lives or in a patient's life or to patients. It could also mean they are the reason for the difference when you consider the phrase, The difference I make with patients. Instead, we chose to interpret this at face value. The question was, describe what makes your work meaningful, and based on other results across the board, this language use is simply different for this profession (medicine) than the other professions (nursing).

\section{Helping others}

We looked at the term Helping in context with patients because physicians used the term enough to exhibit some interesting patterns across the sample (Supplementary Table A3). In their own words, physicians find meaning in: i) Satisfaction of helping others; ii) Patient interaction, helping others; iii) Providing good care to patients and helping them understand their illness; iv) Realize I'm helping people reach their goals; v) Caring and helping others and families in times of need; vi) Helping sick patients.

These patterns suggest that the distance between the physician and the patient is smaller than we originally noted, but still represents a material act of patient care. We must not look past the fact that this group finds meaning in their work through helping patients, making a difference in patients' lives, and having an impact on the patient care endeavor. Whether one owns the relationship by saying my patient or speaking about helping others, we feel that the strength is the same when it comes to describing meaningful work in general, and that is most of the professions in academic medical centers find meaning in work when they are able to make an impact to improve the health and well-being of patients.

\section{Basic scientists}

\section{Science makes my work intrinsically meaningful}

Basic scientists did not use the term patients in any interesting patterns enough to warrant extensive analysis. Though the term patient was not in wide use among this group, when they did use the term, they described a benefit that has not yet emerged. Scientists used the word $p a-$ tient in phrases like, Improving patients' survival, and... contributing to health of patients through research, which, upon further analysis, aligns with interpretation of the first phrase. Using these patterns of language use we can begin to develop an overall theme among this group of respondents. For instance, through an examination of the frequency of the term $m y$, a personal possessive pronoun, we find a deep connection between the basic scientist and 
his/her work and training for a special purpose in life. Supplementary Table A4 supports this interpretation through several distinct statements. Basic Scientists find meaning in their work through: i)...perceiving that my effort leads to something making discovery...; ii) ...applicability of my work as hospitals...; iii) Learn something new everyday with my research...

Basic Scientists in this sample are very confident that their specialized training can lead to special contributions to society, and in this case, a special place in the discovery of new diagnoses, treatments, medications or cures. One might say that basic scientists are not focused on health, but rather disease processes and the science of diseases rather than healthcare for now. To test this notion, we examined word clusters around the term health. This group connects their meaningful work to health using phrases such as: i) [I] can achieve real impact on child health; ii)...ideas with potential to change human health; iii) contributing to health of patients through research; iv) knowledge and info relevant to health [sic] new findings; v) helping the advance [of] health through research.

The discourse analysis on the term health supports the interpretation using the term my above. Basic scientists show confidence in their profession's ability to use their specialized knowledge to combat disease, and in some cases, they work to battle health disparities. The phrase that stands out among all the phrases is, ideas with potential to change human health because it speaks of material actions taken long before they reach the bedside, and to material actions that could have historical impact on the human race (human health). Like their physician counterparts, the distance between the patient and the person providing the service is far greater than it is between nurses and patients. Though this is not surprising, the distance between scientist and patient is always greater because of the lack of interaction with patients per se. From above, scientists see themselves as contributing to the health of patients through new findings, research, and knowledge, all of which in most cases has yet to make it to patients in the short term. Scientists find meaning in impacting health from a distance, and having the ability to provide new solutions to health of the patient in ways that are likely far more advanced than what we have now. Despite these apparent emotional distances between basic scientists and patients, they still find intrinsic meaning in their work through practicing their expertise on a daily basis. It seems they are signaling that the long years of training resulted in a meaningful career whether or not they can see the immediate results of their work, unlike physicians and nurses who can see the more immediate results of their meaningful work. The striking difference between basic scientists and those with direct patient responsibility, therefore, appears to be that meaningful work comes through the process itself rather than some sense of immediate meaning. Meaning to them is more diachronic than synchronic.

\section{Disjuncture: Knowing that I...}

A set of data that seems to show some departure between nurse and physician discourse is the set of word clusters that include the word knowing. For instance, nurses used the word cluster knowing that or knowing that $I$ almost exclusively in terms of knowing that I made a difference; i) knowing that I saved someone; ii) knowing that I impacted a patient's life; iii) knowing that I was helpful; iv) knowing that I give life to patients daily.

Physicians did not use the words knowing that I together or even the term knowing by itself in this context in any of the text data analyzed. The word knowing was solely a part of the word bank used by nurses. Nurses further find meaning in work knowing that they have made a difference in the lives of patients, which is language use that is indicative of a mental process about how these participants see their world. Nurses find a connection with their patients, and their jobs bring them meaning and satisfaction knowing that they have impacted a patient's life.

We are not sure why physicians did not use the knowing that I language, but some of us have offered several interpretations. First, knowing that I've done a good job could also be interpreted as, someone has to tell me I've done a good job to know it or it could be an indicator of humility, or it could be an indicator of the lack of confidence. Second, if we went with these choices, we have to speculate that perhaps the long-term training period physicians must sustain, deletes the knowing that I discourse over time because physicians are trained that they must know and that there is no room for mistakes or there is no room for portraying a lack of confidence. Third, keeping our interpretation positive, we find this is not a very satisfying interpretation because then you have to commit to saying nurses are not as confident, or nurses don't know they've done a good job or are too humble. Finally, the most compelling reason is the difference in the years of training, the levels of decision-making about patients, and the hierarchy. To double check the interpretation that education, training, decisions, and hierarchy might have had something to do with this use of terms, we examined all levels of nursing training and found that only one nurse, who identified as APN, used the phrase knowing that I in this context. The rest were RNs.

We also examined basic scientists who would have similarly equivalent years of training as physicians, and found only one person used the phrase this way: knowing that I am the expert... This phrase is telling because this basic scientist is not saying knowing that I have done a good job, they are saying knowing that I am the expert which in some ways could be interpreted as elitist and without a check or a balance. True, basic scientists are the experts in their work as are physicians, and maybe that level of education, responsibility, and autonomy lends itself to knowing that they are experts instead of knowing that they have done a good job. We could say that being an expert is the same thing as knowing they have done a 
good job or that it carries the same weight whether it is expressed or not. There could be some validity to the interpretation that education levels and hierarchy have something to do with these patterns. Keeping the interpretations positive we concluded that nurses use the phrase knowing that I more likely because of the perspective that they are an important part of the whole treatment picture, have a lower hierarchical position compared to their physician counter-parts, their different educational experiences, and the fact that nurses can tell they have done a good job because of the obvious close relationship to the patient who might offer a thank you, and later an empty hospital bed.

\section{Conclusions}

We can say with confidence that, the health care employees in this organization speak of meaning in work in terms of making a difference in the lives of patients, improving health, either directly through patient care or indirectly through research and discovery, along with having an intrinsic sense of a job well done for helping the lives of patients. This theme is shared across the corpus, regardless of specialty or profession, and probably the most reliable organization level interpretation at this point. We find the most differences, however, at the group level of analysis. For instance, nurses seem to talk about meaning in terms of knowing that they have done a good job or knowing that they have cared for patients, but they also speak of their job as a material process of delivering care that has a measurable, satisfying outcome of a job well-done. Nurses more than any other group seem to connect their knowledge and skills to outcomes, but all of this would be for naught without the relationship to the patient. Meaning in work for nurses is constructed by a continuum of ability, skills, measurable outcomes and relationships. The finding echoes Baldacchino and Haland and Osmundsen who noted that nurses see themselves as catalysts and as those providing a caring presence. ${ }^{23,24}$ These archetypes support this emotional connection that is so prominent in their language about meaningful work. In addition, the connectedness and the knowing that I word clusters are supported by the van Iersel et al..$^{22}$ article in which nurses describe job dimensions important to them such as connectedness and recognition. ${ }^{22}$ Indeed, the knowing that I concept is likely heavily linked to recognition.

Some inferences could be made that physicians see the patient perhaps as a 3-dimensional system (just one interpretation). And though physicians did not use language that emphasizes a strong emotional connection to patients like nurses did, this does not mean that physicians believe they have not done a good job, nor that they do not care about patients. It simply means that their language favors a more material transaction over knowing or caring when it comes to a job well done or caring for patients. Also, perhaps knowing that they have the expertise to experi- ence outcomes or feel that they contributed in a substantive way to positive outcomes is the same as knowing that they have done a good job. The proof is in the patient.

Overall, people in the healthcare workforce find meaning in work in several ways. Some are there to make a difference in the lives of others, and even though they do not see the difference every day, they persist until they can see that they have made a difference, or they persist because the process itself is meaningful, all with outcomes that are yet to be realized when it comes to the patient. It could be said that basic scientists experience meaning diachronically perhaps rather than synchronically because outcomes are at a distance and take time, but still they find meaning in the work along the way. They can see that they have opportunities and abilities to make a difference in the lives of patients whether they share a relationship with them or not. This could finally explain why nurses use the phrase knowing that I have made a difference in the lives of patients makes work meaningful, which is evidence of a mental or cognitive connection to meaningful work through the use of the term knowing. More specifically, nurses seemed to express meaningful work in terms of close connections with patients, while being closely focused on ability to care and outcomes, and knowing that they've done a good job. Physicians were patient focused, and they expressed meaningful work in terms of making a difference and performing the act of patient care. Basic scientists expressed meaningful work in terms of their training and abilities to use science for the betterment of others which adds some validity to from van Iersel et al. ${ }^{22}$ assertions that an environment of continuous learning also contributes to meaningful work, ${ }^{22}$ or Steger et al. ${ }^{7}$ and Martela and Pessi, ${ }^{8}$ who found one does not have to necessarily provide direct help an individual to experience meaningful work.

Overall, the construct of meaningful work in this environment maintains its value in the face of burnout, especially when the healthcare workforce can use their hard-earned knowledge to make a difference in the lives of people, when they can actually see the results of their work, or when they know that their work will contribute in innovative ways in the long term. Meaningful work is therefore more than just taking care of patients. Meaningful work in medicine and healthcare must be a combination of some or all of the following factors (no hierarchy intended): i) Confidence in one's hard earned education and skills; ii) A short and/or long term focus on positive patient outcomes; iii) Connecting with patients; iv) Recognition.

Still, meaningful work maintains its value regardless of the group or actor or burnout, and all are positive, shared results. Our research team believes it would be interesting to stratify the respondents by high burnout scores and low burnout scores and compare responses to gain insight into whether the discourse and the perceptions of meaningful work are different. Further, it might be inter- 
esting to see if healthcare workforce members who score high on burnout use different terms for the term patient, or the term ability, or the phrase my patient.

\section{References}

1. Maslach C, Jackson SE. The maslach burnout inventory. Palo Alto, CA: Consulting Psychology Press; 1986.

2. Maslach C, Leiter MP. Early predictors of job burnout and engagement. J Appl Psychol 2008;93:498-512.

3. Shanafelt T, Boone S, Tan L, et al. Burnout and satisfaction with work-life balance among US physicians relative to the general US population. Arch Intern Med 2012;172:1377-85.

4. Brazeau CM, Shanafelt T, Durning S, et al. Distress among matriculating medical students relative to the general population. Acad Med 2014;89:1520-5.

5. Anderson DL. Organizational development: The process of leading change. 4th ed. Thousand Oaks: Sage; 2016.

6. Cameron KS, Dutton JE, Quinn RE. Positive organizational scholarship. San Francisco: Berrett-Koehler Publishers; 2003.

7. Steger M, Dik B, Duffy R. Measuring meaningful work: The work and meaning inventory (WAMI). J Career Assess 2012;20:322-37.

8. Martela F, Pessi AB. Significant work is about self-realization and broader purpose: Defining the key dimensions of meaninful work. Front Pscyhol 2018;9:363.

9. Hassan M, Bin Nadeem A, Akhter A. Impact of workplace spirituality on job satisfaction: Mediating effect of trust. Cogent Business \& Manag 2016;3:1189808.

10. Duchon D, Plowman DA. Nurturing the spirit at work: Impact on work unit performance author links open overlay panel. Leader Quart 2005;16:807-33.

11. Ashmos D, Duchon D. Spirituality at work: A conceptualization and measure. J Mgt Inquiry 2000;9:134-5.

12. Kazemipour F, Mohd AS. The impact of workplace spirituality dimensions on organisational citizenship behaviour among nurses with the mediating effect of affective organisational commitment. J Nurs Manag 2012;20:1039-48.

13. Snuttjer D. Employee retention tools: Looking beyond radiology. Radiol Manage 2001;23:30-2.

14. Brienza RS. At a crossroads: The future of primary care education and practice. Acad Med 2016;91:621-3.

15. Rasmussen V, Turnell A, Butow P, et al. Burnout among psychosocial oncologists: An application and extension of the effort-reward imbalance model. Psychooncology 2016;25: 194-202.
16. Busis NA, Shanafelt TD, Keran CM, et al. Burnout, career satisfaction, and well-being among US neurologists in 2016 . Neurology 2017;88:797-808.

17. Schrijver I, Brady KJS, Trockel M. An exploration of key issues and potential solutions that impact physician wellbeing and professional fulfillment at an academic center. PeerJ $2016 ; 4$.

18. Jones SK, Griep Y. "I can only work so hard before I burn out." A time sensitive conceptual integration of ideological psychological contract breach, work effort, and burnout. Front Psychol 2018;9:131.

19. Cain CL, Taborda-Whitt C, Frazer M, et al. A mixed methods study of emotional exhaustion: Energizing and depleting work within an innovative healthcare team. J Interprof Care 2017;31:714-724.

20. Jager AJ, Tutty MA, Kao AC. Association between physician burnout and identification with medicine as a calling. Mayo Clin Proc 2017;92:415-22.

21. Bendassolii P. Emptiness and work: A meaning-making perspective. Integr Psychol V Behav Sci 2017;51:598.

22. van Iersel M, Latour CHM, de Vos R, et al. Nursing students perceptions of community care and other areas of nursing practice - A review of the literature. Int J Nurs Stud 2016;61:1-19.

23. Baldacchino D. Spirituality in the healthcare workplace. Religions 2017;8:260.

24. Haland E, Osmundsen TC. Establishing and sustaining collaboration across organizational boundaries within healthcare. Int J Integr Care 2015;15.

25. Tummers LG, Bronkhorst BAC. The impact of leader-member exchange (LMX) on work-family interference and workfamily facilitation. Personnel Rev 2014;43:573-91.

26. Creswell JW, Clark VLP. Designing and conducting mixed methods research. 2nd ed. Thousand Oaks, CA: Sage; 2011.

27. Creswell JW, Poth CN. Qualitative inquiry and resesarch design: Choosing among five approaches. 4th ed. Thousand Oaks,CA: Sage; 2018.

28. Teubert W, Cermakova A. Corpus linguistics: A short introduction. London: Continuum; 2004.

29. Anthony L. AntConc. Tokyo, Japan: Waseda University. 2018;3.5.7. Available from http://www.laurenceanthony. net/software.

30. Thomson G. Introduction to functional grammar. 2nd ed. London: Routledge; 2004.

31. Gee JP. An introduction to discourse analysis: Theory and method. 4th ed. London. New York: Routledge; 2014.

32. Saldana J. The coding manual for qualitative researchers. London. Thousand Oaks: Sage; 2016. 